\title{
Reaplicabilidade de Tecnologias Sociais em Perspectiva com Redes Sociais: Análise de experiências na Colômbia e Brasil
}

\section{Patrícia C. Fernandes*, Oswaldo Gonçalves Junior.}

\section{Resumo}

Mediante à luz das adversidades relacionadas à habitação na América Latina, principalmente no Brasil e na Colômbia, o projeto procura estudar as tecnologias sociais como possíveis alternativas para problemática habitacional através do entendimento do elo entre "tecnologia social" e "redes sociais". Sendo assim, busca-se analisar a reaplicabilidade de tais experiências por intermédio da compreensão de redes, de modo a concluir sobre os possíveis direcionamentos dos governos e das demais esferas envolvidas na temática

\section{Palavras-chave:}

Tecnologia social, redes, habitação.

\section{Introdução}

As condições habitacionais em países da América Latina, como Brasil e Colômbia, se apresentam como precárias, sobretudo entre as camadas mais pobres da população. Dado a insuficiência das políticas públicas e a ampliação da participação da sociedade civil têm impelido 0 surgimento de alternativas tecnológicas - as chamadas tecnologias sociais - para o enfrentamento deste e outros problemas.

Como parte do entendimento da problemática está o elo entre "tecnologia social", compreendida como "produtos, técnicas ou metodologias reaplicáveis, desenvolvidas na interação com a comunidade e que representem efetivas soluções de transformação social" (FBB, 2017, p.1). e "redes sociais", por sua vez, como uma estrutura social composta por pessoas ou organizações, interligadas por um ou vários tipos de relações, que conecta diferentes recursos em torno de um propósito comum. Frente a tais referenciais buscase analisar experiências de tecnologia social no Brasil e na Colômbia voltadas para o enfrentamento de problemas habitacionais, em sua interface com o fenômeno das redes sociais, tendo em vista melhor compreender limites e alcances desses arranjos na reaplicação de tais tecnologias, sobretudo em circunstâncias de vulnerabilidade habitacional

\section{Resultados e Discussão}

Por meio da pesquisa em páginas eletrônicas e posterior aplicação de um filtro foi possível catalogar sete experiências que se enquadram no perfil de tecnologias sociais no Brasil e Colômbia. Conforme a tabela:

Tabela1. Tecnologias Sociais - Brasil e Colômbia

\begin{tabular}{|c|c|}
\hline Brasil & Colômbia \\
\hline Aquecedor Solar de Baixo & EkomuroH2O+; Eco \\
Custo; Fossa Séptica & Techos \\
Biodigestora; Jardins & \\
Filtrantes; Calha & \\
Alternativa; Casas & \\
Adaptadas à Eventos & \\
Climáticos Extremos & \\
\hline
\end{tabular}

Das experiências analisadas, destaca-se como desenvolvedores organizações da sociedade civil
(ONG/OSCIP) e empresas ou negócios sociais. Já relativo à motivação há um enfoque para a consciência ambiental e a necessidade da população local, como principais incentivos.

No que tange aos custos, as tecnologias possuem custos de construção e manutenção baixos. Em relação ao financiamento, este se apresenta de forma bastante diversificada. Entretanto, um fator notório nos resultados é em relação ao apoio não financeiro. Em todas as tecnologias que se apresentaram como mais frutíferas, foi possível perceber 0 apoio de universidades, do governo ou de prêmios internacionais. Ademais, as experiências que mostraram canais de comunicação mais estruturados são aquelas que possuem maior interface com o governo, sendo este financiador ou apoiador.

Todas experiências em análise foram reaplicadas, em maior ou menor escala e apresentam a disseminação como objetivo. Tal fato é impulsionado por estas poderem ser reaplicadas de maneira idêntica em qualquer localidade e não posuirem patente ou esta ser de proteção aberta.

Vale na análise dos resultados a interface com as políticas públicas, pois a tecnologia mais reaplicada e com uma rede mais estruturada era parte de uma política pública do Ministério das Cidades.

\section{Conclusões}

Portanto, é possível observar envolvimento do governo e universidade como essenciais para maior reaplicabilidade e manutenção de uma comunicação eficiente entre os atores envolvidos na rede, de modo a favorecer o fortalecimento desta.

\section{Agradecimentos}

À Pró Reitoria de Pesquisa (PRP), ao Conselho Nacional de Desenvolvimento Científico e Tecnológico (CNPQ) e ao Laboratório de Estudos do Setor Público (LESP).

Fundação Banco do Brasil. Edital do Prêmio "Fundação Banco do Brasil de Tecnologia Social 9a Edição" (2017). Disponível em:\&lt;http://tecnologiasocial.fbb.org.br/tecnologiasocial/principal.htm\&gt; Acesso em 12 fev 2018. 